\title{
ВОЗМОЖНОСТИ ЦИФРОВОЙ ЭКОНОМИКИ В ИННОВАЦИОННОЙ ПОЛИТИКЕ НОВОГО ПОКОЛЕНИЯ
}

\section{VECTOR OF FUNDAMENTAL CHANGES IN THE DIGITAL ECONOMY}

\section{S. Doguchaeva}

Summary. Today, according to leading analysts, the promotion of cloud infrastructure is a serious innovation, creating a new model that effectively affects the development of the digitalization of the economy. In turn, artificial intelligence has already revolutionized the way people work today. From optimizing business operations to improving decisionmaking processes, it has shown real potential in various sectors of the country's economy.

Keywords: business processes, digital economy, cloud technologies, legislative practice, artificial intelligence, business forecasts, hybrid clouds, machine learning.
$\mathbf{P}$ ешить глубинные проблемы, сдерживающие развитие, помогут использование преимуществ интернета, развитие цифровой экономики, стимулирование равновесия спроса и предложения, объединение основных инновационных факторов, оптимальное распределение ресурсов. [1] Сегодня в стране интеграция между цифровой экономикой и традиционным производством по требованию рынка создает новые модели управления в интеграции сетей и производства, крупномасштабном производстве по индивидуальному заказу, в удаленном интеллектуальном обслуживании и пр.

Согласно исследованию PwC, в 2030 году мировой ВВП вырастет на $14 \%$ благодаря повсеместному внедрению технологий искусственного интеллекта и машинного обучения. Это принесет дополнительные 15,7 трлн. долларов в экономику. [3]

Нынешнее воздействие и потенциал искусственного интеллекта, технология искусственного интеллекта произведет революцию в ближайшие годы. Эксперты ожидают, что к 2022 году глобальные расходы на искусственный интеллект, к примеру, в ритейле вырастут до $\$ 7,3$ миллиарда в год. [5] Розничные системы экономики используют виртуальную реальность и расширенную функциональность в рекламе, каталог продуктов сегодня растет, и покупатели знакомятся с продуктами перед покупкой. Ожидается, что к 2022 году чат-боты будут
Догучаева Светлана Магомедовна

К.ф.-м.н., дочент, Финансовый университет при Правительстве Российской Федерачии, г. Москва sv-doguchaeva@yandex.ru

Аннотация. Сегодня, по мнению ведущих аналитиков, стимулирование облачных инфраструктур - это серьезная инновация, создающая новую модель, которая эффективно влияет на развитие цифровизации экономики. В свою очередь, искусственный интеллект уже произвел революцию в том, как люди работают сегодня. От оптимизации бизнес-операций до улучшения процессов принятия решений — он показал реальный потенциал в различных отраслях экономики страны.

Ключевые слова: бизнес-процессы, цифровая экономика, облачные технологии, искусственный интеллект, бизнес-прогнозы, гибридные облака, машинное обучение.

осуществлять 85\% всех взаимодействий с клиентами. Сегодня по мнению ведущих аналитиков, искусственный интеллект изменит способ обработки информации в финансовых учреждениях. Банки используют роботизированную автоматизацию процессов (RPA) для обработки стандартизированной информации в таких областях, как выверка и консолидация.

Как показано в [7], в будущем финансовые учреждения планируют использовать искусственный интеллект для составления квартальных отчетов о прибылях и убытках. Искусственный интеллект также играет активную роль в стратегических процессах. Технологии позволяют фирмам выполнять финансовый анализ, распределять активы и составлять прогнозы в режиме реального времени, и как следствие, будут изменены подходы финансовых консультантов и инвестиционных компаний к потенциальным клиентам.

Обрабатывающая промышленность имеет огромный потенциал в сфере производства: от профилактического обслуживания оборудования до автоматизации задач, выполняемых человеком. Искусственный интеллект способен дать возможность заводам работать эффективнее и снизить количество ошибок на производстве. К примеру, инициативы технологических гигантов, таких как Microsoft (AІ для доступности), и небольших компаний произвели революцию в области искусственного интеллекта для всех информационно-технических работников. 
Сегодня технологии и программное обеспечение, многие стартапы и крупные компании используют искусственный интеллект, для переноса в строительную отрасль в будущее.[4] За счет уменьшения количества человеческих ошибок и использования больших данных, внедрение искусственного интеллекта и машинного обучения, делает процесс строительства более быстрым, безопасным и рентабельным.

По мнению ведущих ИТ-экспертов цифровой отрасли экономики, искусственный интеллект может быть внедрен в интеллектуальные электрические сети для более эффективного энергоснабжения и прогнозирования поломок оборудования. Внедрение искусственного интеллекта упростит исследование энергетики, а также откроет новые возможности для экономии. Крупные ведущие компании, смотрят в будущее, чтобы использовать искусственный интеллект для оптимизации выработки электроэнергии из батарей и точек потребления. Согласно аналитике Bloomberg News, технологии искусственного интеллекта в энергетике и горнодобывающей промышленности могут в конечном итоге сэкономить \$200 миллиардов.

Ведущие специалисты в экономике и информационных технологиях исследовали проблемы возможностей гибридного облака в экономике. [2] В то время как гибридное облако считается идеальной ИТ-моделью для цифровой экономики, данные отчета указывают на большие сложности в его использовании: 69\% компаний полагают, что трансформация занимает больше времени, чем ожидалось. Однако 95\% респондентов уверены, что выиграют от гибридного подхода при условии обеспечения согласованной работы и сквозных операций в разных облачных средах, связанных прежде всего, с цифровизацией экономики. По мнению исследователей, это позволит решить множество проблем, с которыми копании столкнулись: от изолированных операционных сред до кадрового дефицита. [8]

Исследования отмечают в целом более низкий уровень проникновения облаков в регионе страны в целом и, соответственно, гибридных в частности. [6] При этом российские компании, которые используют модель гибридного облака, сталкиваются ровно с теми же трудностями, что и их коллеги по всему миру. Во-первых, это проблемы перемещения и управления приложениями и данными из-за разных стандартов и применяемых технологических платформ в компаниях. Во-вторых, одинаково сложно, если возможно, найти специалистов, владеющих всем облачным стеком и в целом, знающих экономическую составляющую в компании, все это приводит к тому, что переход на новую модель на начальном этапе настораживает необходимостью дополнительных инвестиций в новые компетенции.
Большинство респондентов обеспокоены работой критически важных бизнес-приложений в общедоступном облаке - особенно в отношении надежности, переносимости и стоимости. Кроме того, некоторые компании не могут перенести в такое облако критически важные приложения из-за сложности цены или по соображениям безопасности или требований регуляторов в той или иной области экономики и финансов.

Среди главных проблем гибридного облака 75\% опрошенных указывали на необходимость реинжиниринга приложений или платформ и $71 \%$ - на сложность процесса миграции. Компании испытывают дефицит квалифицированных ИТ-специалистов, но проблема усугубляется, когда приходится искать кадры, способные управлять инфраструктурой как публичного, так и частного облака. 88\% компаний сталкиваются с проблемами обеспечения навыков у ИТ-персонала для управления гибридной инфраструктурой, и 53\% считают это главной проблемой. [9]

В то время как популярность гибридных облачных платформ и искусственного интеллекта быстро растет, потребности клиентов в покупке прикладных и инфраструктурных сервисов отличаются очень сильно, заметили ведущие специалисты-эксперты экономики и ИТ-сферы. Сегодня, как считают аналитики, в цифровой экономике самое подходящее время для формирования ведущих компаний на рынке информационных технологий, ориентированные на то, что они делают лучше всего. Ведущие игроки рынка твердо нацелены на создание бизнеса в области гибридных облаков с большой стоимостью.

Учитывая, что разные навыки требуются для управления частными и публичными облаками, компаниям приходится использовать для их поддержки разные команды, что приводит к изолированности сред, с чем столкнулось 95\% респондентов. Такой подход приводит к операционной неэффективности: 49\% респондентов отметили увеличение необходимых ресурсов, 45\% увеличение затрат и $43 \%$ отметили растрату ресурсов.

Кроме того, для 88\% опрошенных лицензирование программного обеспечения является важным аспектом в построении гибридной ИТ-инфраструктуры. 58\% столкнулись с трудностями, связанными с лицензированием, и также $58 \%$ - с зависимостью от поставщика при переходе в публичное облако. $65 \%$ респондентов готовы рассмотреть возможность использования модели подписки при лицензировании ИТ-решений.

Сегодня, как считают ведущие специалисты в сфере цифровой экономики, компании должны ориентироваться на гибкость, важнейшим аспектом которой 
является децентрализация ресурсов и их высокая доступность. [11] Бизнес может использовать публичные и частные облака или даже периферийные вычисления, чтобы разместить ИТ-инфраструктуру именно там, где она больше всего нужна. Но, как показало исследование, эта гибкость возможна только при обеспечении совместимости компонент, общего инструментария и возможности сквозных операций в нескольких облаках, что и делает гибридную облачную среду идеальной. Портфель предлагаемых продуктов и SLA-ориентированный подход неизбежно приведут к желанию ИТ-менеджеров компаний воспользоваться этой услугой.

Индустрии, которые будут преобразованы революцией искусственного интеллекта и цифровой экономики в ближайшие годы - это переопределяет целые отрас- ли экономики, автоматизируя процессы и трансформируя работу бизнеса. [10] У искусственного интеллекта и облачных технологий открываются огромные возможности для расширения человеческого потенциала, используя уникальные способности к творчеству и ловкости - характеристики, которые трудно воспроизвести компьютеру.

Эксперты прогнозируют, что сегодня искусственный интеллект и машинное обучение окажут положительное влияние на рост, производительность, инновации и создание новых рабочих мест в стране. Следует отметить, что проекты для крупных компаний, как правило, носят индивидуальный характер, в то время как представители этих компаний приобретают базовые типовые продукты. [12]

\section{ЛИТЕРАТУРА}

1. Противоречивые гибридные облака// (Электронный ресурс). Режим доступа: https://www.comnews.ru/content/209356//свободный (дата обращения 01.03.2021).

2. 10 отраслей экономики, где искусственный интеллект совершит революцию// (Электронный ресурс). Режим доступа: https://hub.forklog.com/10-otraslejekonomiki-gde-iskusstvennyj-intellekt-sovershit-revolyutsiyu// свободный (дата обращения 15.03.2021).

3. Будущее потребительских рынков// (Электронный ресурс). Режим доступа: https://www.pwc.com// (PwC)// свободный (дата обращения 26.03.2021).

4. Лучшие тренды и технологии в программировании// (Электронный ресурс). Режим доступа: https://itproger.com/news/luchshie-trendi-i-tehnologii-vprogrammirovanii// свободный (дата обращения 20.03.2021).

5. 0бзор российского ИТ-рынка // (Электронный ресурс). Режим доступа: https://www.idc.com/cis// свободный (дата 0бращения 30.03.2021).

6. Противоречивые гибридные облака// (Электронный ресурс). Режим доступа: http://www.tsconsulting.com/press/articles/protivorechivye-gibridnyeoblaka// свободный (дата обращения 12.03.2021).

7. Искусственный интеллект изменят бизнес в ближайшем будущем // (Электронный ресурс). Режим доступа: https://lookatnews.info/post/ / свободный (дата обращения 01.04.2021).

8. Рост гибридных облаков (Электронный ресурс). Режим доступа: https://www.cnews.ru/reviews/cloud2015/articles/oblaka_rastut_poka_itrynok_ stagniruet// свободный (дата обращения 06.04.2021).

9. Система управления Искусственным интеллектом // (Электронный ресурс). Режим доступа: https://ria.ru/20191107/1560642841.html// свободный (дата обращения 12.03.2021).

10. Что может ИИ и машинное обучение в 2021 году// (Электронный ресурс). Режим доступа: https://www.reg.ru/blog/chto-mozhet-ii-i-mashinnoe-obucheniev-2021-godu// свободный (дата обращения 29.03.2021).

11. Цифровая грамотность россиян//(Электронный ресурс). Режим доступа: https://nafi.ru/analytics/tsifrovaya-gramotnost-rossiyan-issledovanie-2020// cвободный (дата обращения 03.04.2021).

12. Экономика управления большими данными // (Электронный ресурс). Режим доступа: https://oecd-russia.org/analytics/ekonomika // свободный (дата 0бращения 11.03.2021).

(c) Догучаева Светлана Магомедовна ( sv-doguchaeva@yandex.ru ). Журнал «Современная наука: актуальные проблемы теории и практики» 